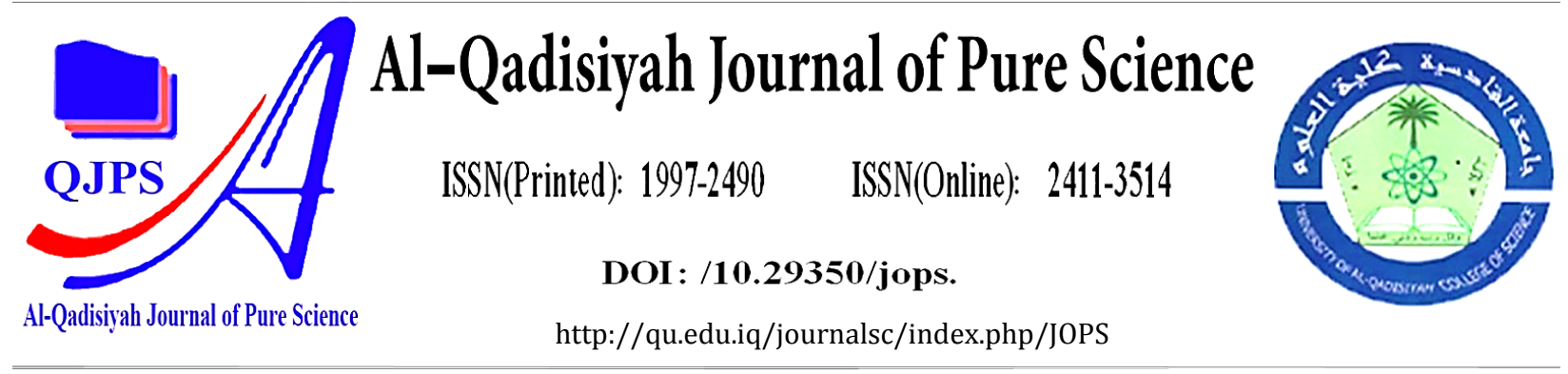

\title{
The First Confirmed Record of Shikra Accipiter badius (Gmelin, 1788) in Iraq
}

\section{Authors Names \\ a. Mudhafar A. Salim \\ b. Salwan Ali Abed \\ c. Zaman Salman Harbi \\ Article History}

Received on: $16 / 02 / 2020$

Revised on: 20/03/2020

Accepted on: 25/03/2020

Keywords:

Shikra, Accipiter badius,

Ad-Daghara, IOCN, Iraq

DOI: https://doi.org/10.29350/ jops.2020.25. 2.1083

\begin{abstract}
Over the period of 2015-2020, and during the series of the field surveys arranged and conducted by the Iraqi Organization for Conservation of Nature (IOCN) in various locations and habitats in Iraq, IOCN team had the opportunity to survey various areas within Iraq in different seasons where new observations of bird species were made as the first records for Iraq; additionally, the team have also discovered new breeding evidences and expansions within different habitats in Iraq. During one of these surveys is central Iraq, specifically at the Middle Euphrates region, an individual of Shikra Accipiter badius was observed in the extreme north of Al-Qadisiyah province, Ad-Daghara sub-district. This paper confirms, through the details of the observation and description provided below, the first confirmed record of this species for Iraq.
\end{abstract}

\section{Introduction}

Shikra Accipiter badius is a member of the Family Accipitridae that includes small to medium-sized raptors spread over nearly wide range worldwide. Shikra is Least Concern bird (LC) species which is a widespread resident breeder throughout south Asia and sub-Saharan Africa [11,14]. Within the Middle East, Shikra is a rare passage migrant to the area, and vagrant to Israel and Oman [13]. It has been found in Iran, Kuwait, Turkey, Yemen, and the UAE [12,13,7]. The closest breeding grounds of this species are in Armenia, southeast Azerbaijan, northeastern Iran, and the UAE [4,3,10,13] where there might be an expanding breeding population at the UAE [7]. Around Iraq, Shikra has been observed in Iran, Turkey, Saudi Arabia [12,13,8]. Shikra breeds late in the dry season and early in the wet season, although this means at opposite sides of the equator in different months of the year [9,17,6,5], Brown et al., [6] indicated that Shikra may breed at one year of age, while Thiollay (1975) suggested that some birds do not breed at one year of age. Some bird species have been mentioned in past publications on birds of Iraq, of which Shikra was one of them, but no references to the original records have been found; therefore, the decision was taken by the authors to exclude them from the updated checklist of the birds of Iraq [15]. Additionally, neither Salim et.al. [16] nor Allouse [1,2] 
have mentioned this bird species within the Iraqi bird checklists. This paper, along with the detailed description and confirmation, represents the first confirmed observation of Shikra for Iraq.

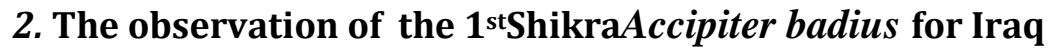

While birding within the northern parts of Al-Qadisiyah province in the Middle Euphrates, in the northern parts of Ad-Daghara subdistrict around the coordinates (N: 32॰12'32", E: 4447'49"), IOCN team have spread out within the observation area to the north of Daghara River. After period of birding time, one of the members of the team (MS) was able to spot a flying Accipiter that was first thought to be Eurasian Sparrow Hawk Accipiter nisus. The bird has been flushed out by the movement of MS after it was perching on a date-palm at the edge of an orchard, and immediately flew away eastward crossing over open field area. Right away, MS has walkie-talkie called SA that an Accipiter has flown towards the area he and ZS are birding at. After a while, the bird was photographed by the birders while the bird was crossing heading to a nearby date-palm orchard. Later on, and after checking the photos, it seemed that the observed Accipiter was juvenile based on the key features detailed below.

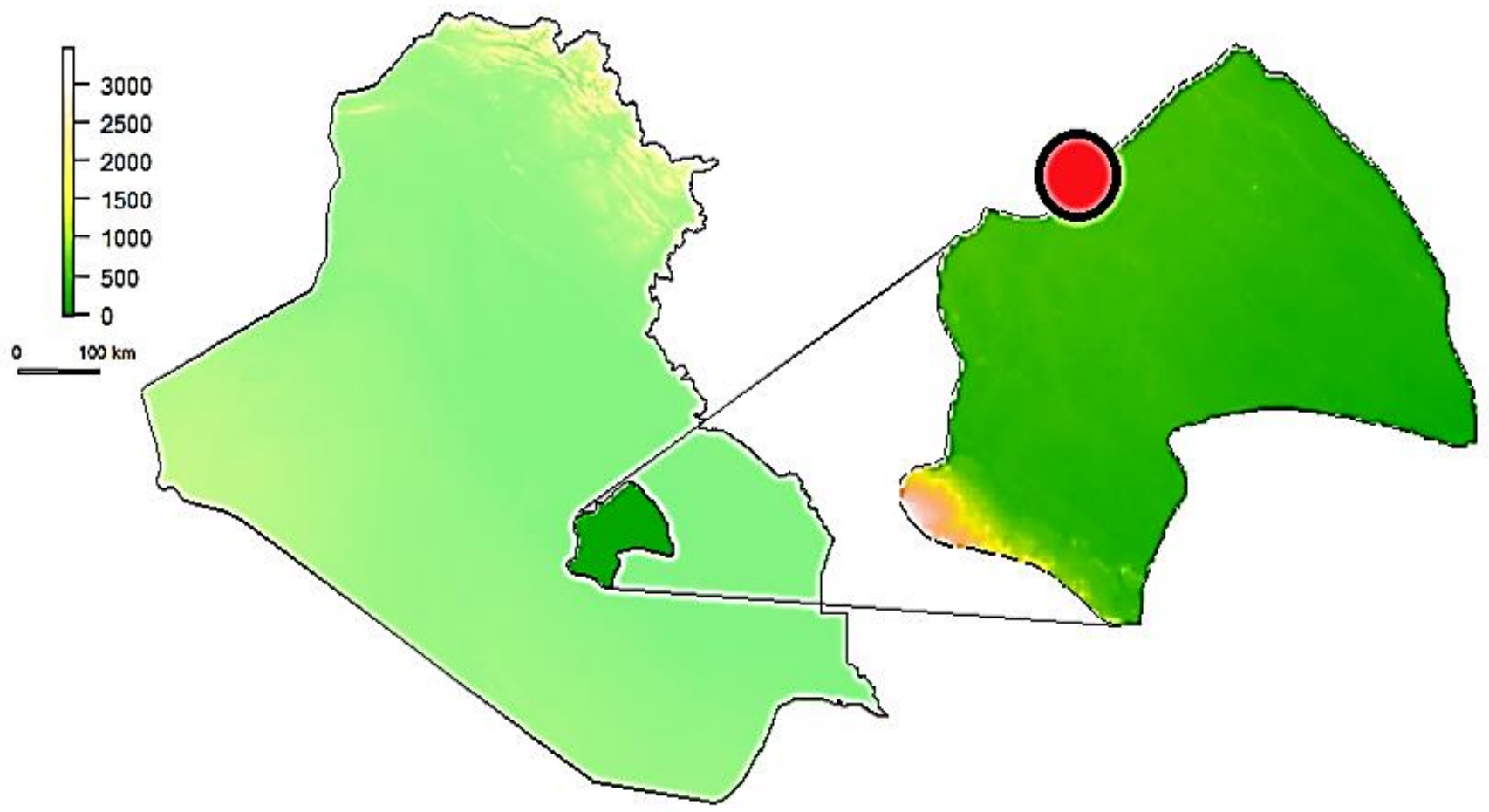

Figure. 1: Iraq Map shows the location of Al-Qadisiyah province and the location where the fist Shikra Accipiter badius was observed in Iraq.

The observation was made at the $29^{\text {th }}$ of September 2019, within an agricultural area with patches of dense date-palms orchards interspersed with open areas of crops and arid areas with no plant cover. The area also consists of open arid-lands, mainly salt-crested, with scattered Tamarix shrubs. Many flocks of small Passerines were found in this area, and there is a reedbed at the southern edge of the river that seems to be key roosting area for Sparrows. The observation area lies $15 \mathrm{~km}$ to the northwest of Ad-Daghara center, $3.4 \mathrm{~km} 4 \mathrm{~km}$ southwest of Sadr Ad-Daghara barrage. 


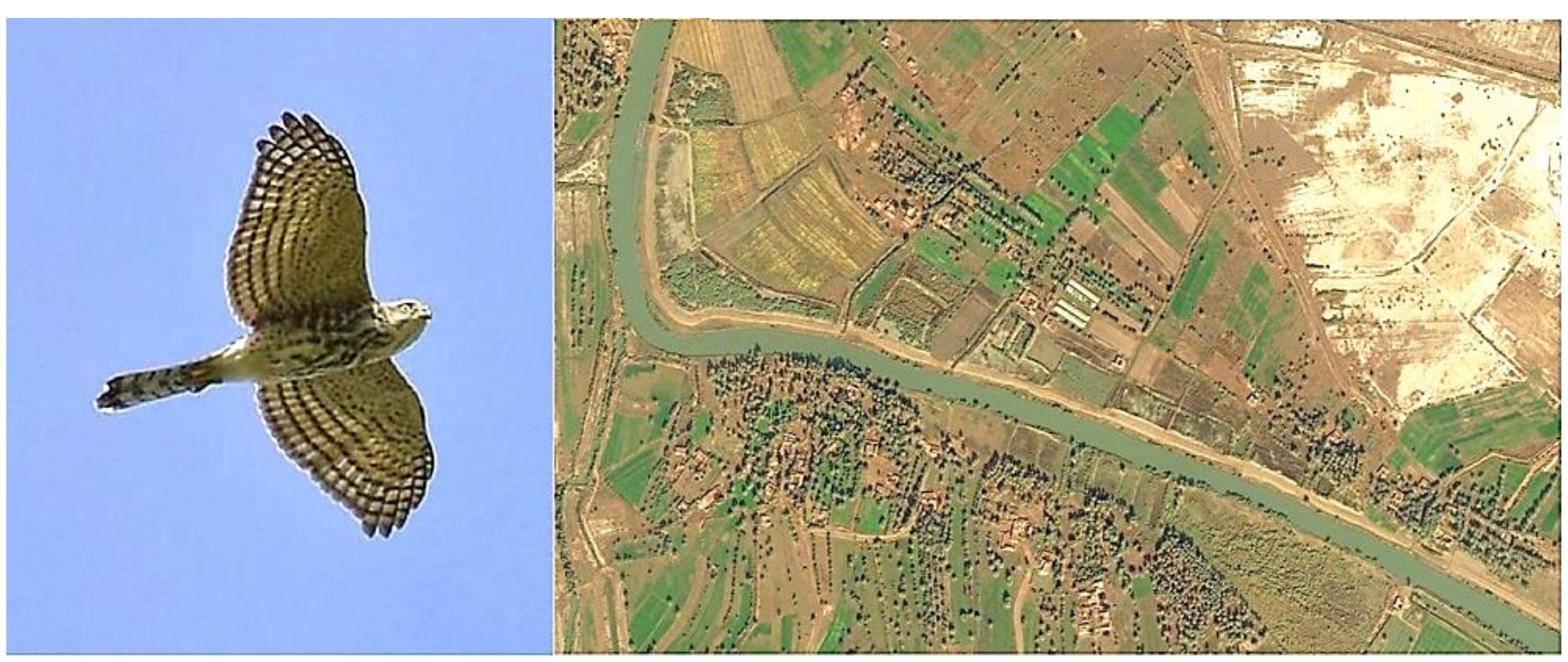

Figure 2: Left: The1st juvenile Shikra observed in Iraq; Right: Satellite image shows the location where the 1st Shikra Accipiter badius was observed. CIOCN.

The observed individual was a juvenile bird. It was recognized based on the broad wings and the formula of the wing having five 'free' primaries (fingers), whereas the Levant Sparrowhawk has only four; the shape of the tail with elongated central tail feathers; the way of flying being similar to Sparrowhawk. The dark, longitudinal, spots on the underparts are very obvious - like the underparts of juvenile Goshawk, but Goshawk differs from the observed bird in size, wing-shape, and the number of the under-tail bands. The wing-tip is rather rounded in comparison with Levant Sparrowhawk that has rather pointed tip. Finally, it can be easily recognized as Shikra juvenile due to the yellow iris (obvious in the photo) as Levant Sparrowhawk juveniles have brown iris.

Conflict of Interest: The authors declare that they have no conflict of interest.

\section{Acknowledgements:}

We are very grateful for the continuous support and encouragement made by the Iraqi Organization for Conservation of Nature (IOCN), the Arab-Regional Centre for World Heritage, and the College of Sciences, University of Al-Qadisiyah. We also deeply thank the locals and persons who helped us during the continuous surveys that were conducted by IOCN. Last, but not least, thanks to Mr. Richard Porter for his kind time in reviewing the manuscript and making additional hints for the identification.

\section{References:}

[1] Allouse, B. 1953. The Avifauna of Iraq. Iraq Natural History Museum, Baghdad.

[2] Allouse, B. 1960. [Birds of Iraq]. Vol. I. Al-Rabita Press, Baghdad. [In Arabic]

[3] Ananian, V, K Aghababyan, S Tumanyan, G Janoyan\& K Bildstein. 2010. Shikra Accipiter badius breeding in Armenia. Sandgrouse 32: 151-155.

[4] Aspinall, S. 1997. Shikra breeding in the United Arab Emirates. Phoenix 14: 10-11.

[5] Allan, L.G. 1997. Little Banded Goshawk. Pages 226- 227 in J.A. Harrison, D.C.. Underhill, M. Herremans, AJ. Tree, V. Parker, and CJ. Brown [EDs.], The atlas of southern African birds. Vol. I. BirdLife South Africa, Johannesburg, South Africa.

[6] BROWN, L.H., E.K. UPOn4, AND K. NEWMan. 1982. The birds of Africa. Vol. I. Academic Press. London, U.K.

[7] Campbell, O. 2019. Recent sudden expansion in the breeding range of ShikraAccipterbadius in the UAE. 
[8] Clark, W.S. and Parslow, R. 1991. A specimen record of Shikra Accipter badius for Saudi Arabia. Sandgrouse, 13: 44-6.

[9] ELGOODJ, H., C.H. FRY, ND RJ. DOWSETT. 1973. African migrants in Nigeria. Ibis 115:1-45.

[10] Heiss, M \& K Gauger. 2009. The rediscovery of breeding Shikras Accipiter badius in the Western Palaearctic. Sandgrouse 31: 134-137.

[11] Herremans M \&Louette, M. 2000. A partial post-juvenile molt and transitional plumage in the shikra (Accipiter badius) and Grey Frog Hawk (Accipiter soloensis) (PDF). Journal of Raptor Research. 34 (4): 249-261.

[12] LUKE (DOğAn) Smith. 2012. Two shikra Accipiter badius records from turkey. Sandgrouse 34 (2012).

[13] Porter, R \& S Aspinall. 2010. Birds of the Middle East. Christopher Helm, London.

[14] Rasmussen, PC \&Anderton, JC. 2005. Birds of South Asia. The Ripley Guide. Volume 2. pp. 350-351.

[15] Salim MA, Al-Sheikhly OF, Majeed KA, Porter RF. 2012. An annotated checklist of the birds of Iraq. Sandgrouse. 2012; 34:4-43.

[16] Salim, MA, R Porter, P Schiermacker-Hansen, S Christensen \& S Al- Jbour. 2006. [Field guide to the birds of Iraq].NI/BirdLife International, Baghdad. [In Arabic].

[17] SMEENK, C., AND N. SMEENI-ENSERINK. 1977. Observa6ons on the Shikra Accipiter badius in Nigeria. Ardea6 5:148-164.

[18] THIOLLAYJ., M. 1975. Les rapacesd 'une zone de contact savane-fort en C6te-d'Ivoire: densitY, dynamiqueetstructure du peuplement. Alauda 43:387-416. 